\title{
Depth distribution of larvae critically affects their dispersal and the efficiency of marine protected areas
}

\author{
Hanna Corell ${ }^{1, *}$, Per-Olav Moksnes ${ }^{2}$, Anders Engqvist ${ }^{3}$, Kristofer Döös ${ }^{1}$, \\ Per R. Jonsson ${ }^{4}$ \\ ${ }^{1}$ Department of Meteorology, Stockholm University, Stockholm 10691, Sweden \\ ${ }^{2}$ Department of Biology and Environmental Sciences, University of Gothenburg, Box 461, Göteborg 40530, Sweden \\ ${ }^{3}$ Department of Land and Water Resources Engineering, Royal Institute of Technology, Stockholm 10044, Sweden \\ ${ }^{4}$ Tjärnö Marine Biological Laboratory, Department of Biology and Environmental Sciences, University of Gothenburg, \\ Strömstad 45296, Sweden
}

\begin{abstract}
This study aims to improve estimates of dispersal by including information on larval traits, and in particular to explore how larval depth distribution affects connectivity and MPA (marine protected area) functionality in the Baltic Sea. A field survey showed that both invertebrates and fish differed in their larval depth distribution, ranging from surface waters to $>100 \mathrm{~m}$. A biophysical model of larval dispersal in the Baltic Sea showed that decreased depth distribution increased average dispersal distance 2.5 -fold, decreased coastal retention and local recruitment, and substantially increased connectivity. Together with pelagic larval duration (PLD), depth distribution explained $80 \%$ of total variation in dispersal distance, whereas spawning season, and geographic and annual variations in circulation had only marginal effects. Median dispersal distances varied between 8 and $46 \mathrm{~km}$, with $10 \%$ of simulated trajectories dispersing 30 to $160 \mathrm{~km}$ depending on drift depth and PLD. In the Baltic Sea, the majority of shallow Natura 2000 MPAs are $<8 \mathrm{~km}$ in diameter. In the present study, only 1 of the 11 assessed larval taxa would have a recruitment $>10 \%$ within MPAs of this size. Connectivity between MPAs was expected to be low for most larval trait combinations. Our simulations and the empirical data suggest that the MPA size within the Natura 2000 system is considerably below what is required for local recruitment of most sessile invertebrates and sedentary fish. Future designs of MPA networks would benefit from spatially explicit biophysical models that consider dispersal and connectivity for complex circulation patterns and informed larval traits.
\end{abstract}

KEY WORDS: Larval dispersal · Pelagic duration time - Vertical distribution · Field survey · Biophysical model $\cdot$ Hydrodynamics $\cdot$ Marine protected area $\cdot$ Conservation biology

\section{INTRODUCTION}

The world's marine ecosystems are under severe pressure from habitat destruction, pollution, overfishing and climate change (Lotze et al. 2006, Halpern et al. 2008). Nature reserves, marine protected areas (MPAs) and no-take areas are considered effective instruments to mitigate the loss of biodiversity and to restore overexploited stocks (Lester et al. 2009), although there are worries that they may not be suffi- cient to reverse the overall biodiversity loss (Mora \& Sale 2011). Nevertheless, it is important that networks of MPAs are designed as efficiently as possible with regard to persistence of target species. Classic questions in the design of nature reserves and protected areas are location, size and number of selected areas (e.g. Diamond 1975). Design of protected areas becomes particularly complex when target species show long-distance dispersal, like many marine invertebrates and fish (Kinlan \& Gaines 2003). 
Most sedentary marine macroorganisms form partially open local populations (e.g. Caley et al. 1996, Kritzer \& Sale 2004) connected in metapopulations through dispersal by planktonic spores and larvae. Dispersal and connectivity are increasingly recognised as key factors for local population dynamics (Cowen et al. 2006) and population persistence (Hanski 1999, Carson et al. 2011). Understanding dispersal and, in particular, the source-sink dynamics of metapopulations are therefore considered critical for conservation and restoration of marine populations (Lipcius et al. 2008, Lipcius \& Ralph 2011). There is also a general call for including connectivity as an important conservation criterion when selecting MPAs (Roberts 1997, Gaines et al. 2003, Almany et al. 2009). To date, an often implicit assumption is that populations within selected MPAs will persist through local survival, reproduction and recruitment (e.g. review by Botsford et al. 2009). The validity of this assumption critically depends on the relative scales of MPA size and propagule dispersal distance (Kritzer \& Sale 2004, Palumbi 2004, Moffitt et al. 2011). Most MPAs in coastal areas tend to be rather small; the 298 MPAs along the European Atlantic coast have a median area of only $7.6 \mathrm{~km}^{2}$ (Johnson et al. 2008), and the 443 MPAs in the Baltic Sea have a median area of $15 \mathrm{~km}^{2}$ (HELCOM 2009). A crucial question is whether individual MPAs or networks of MPAs are biologically functional, i.e. whether they have the capacity to sustainably protect target populations. Clearly, lifehistory traits that influence dispersal distance and connectivity should determine the efficiency of MPAs depending on their size and location (Lockwood 2002, Shanks et al. 2003, Almany et al. 2009, Moffitt et al. 2011).

The transport of larvae among local populations is a complex function of ocean circulation, larval behaviour and the duration of the planktonic stage (Shanks 1995). Recent empirical studies have demonstrated that most pelagic larvae are not passively transported during larval development but rather show vertical swimming behaviours that lead to species-specific vertical distribution of larvae that may change with ontogeny or with diel or tidal cycles (Forward \& Tankersley 2001, Morgan 2001, Sale \& Kritzer 2003, Queiroga \& Blanton 2005). Because the velocity and direction of coastal ocean currents often vary with depth, the vertical position of pelagic propagules may critically affect their dispersal. However, our understanding of larval behaviour and its interaction with oceanographic processes is still limited to a handful of marine species, mainly decapod crustaceans and a few fish species (Forward \&
Tankersley 2001, Sale \& Kritzer 2003, Queiroga \& Blanton 2005). For a large majority of species, the vertical distribution of larvae is unknown, which poses a serious impediment for understanding larval dispersal and connectivity in marine populations. The effect of larval behaviour on dispersal has yet to be included in designs of marine reserves. Propagules of most marine species are microscopic and may disperse for days to several weeks, leading to low concentrations in the water column. Dispersal distance and connectivity are thus difficult to estimate empirically, and the methods are often costly and suffer from limited spatial and temporal coverage; therefore, marine connectivity is increasingly estimated from biophysical models including ocean circulation (Roberts 1997, Paris et al. 2007, Cowen \& Sponaugle 2009).

Several previous papers have modelled the dispersal and connectivity of single species, often with the aim to understand recruitment dynamics of commercial fish and shellfish (e.g. Bolle et al. 2009, Incze et al. 2010, Savina et al. 2010). More general studies have explored how dispersal distance is affected by larval vertical behaviour (e.g. Fiksen et al. 2007, Paris et al. 2007), spawning time (Edwards et al. 2007), pelagic larval duration (Edwards et al. 2007, Mitarai et al. 2008) and spawning location (Aiken et al. 2007, Edwards et al. 2007). Only a few studies have modelled how dispersal and connectivity may affect the selection of MPAs (e.g. Stockhausen et al. 2000, Hastings \& Botsford 2003, Robinson et al. 2005, White et al. 2010, Moffitt et al. 2011). However, to our knowledge, there are no studies that have used spatially explicit biophysical modelling to find relations between larval depth distributions and minimum MPA size.

In the present paper, we explore with realistic simulations of larval dispersal, in a fully factorial design, how dispersal and local recruitment in MPAs are expected to depend on the depth distribution of drifting larvae. The effect of larval depth distribution on dispersal is compared with effects of spawning season and pelagic larval duration together with spatial and temporal variability in ocean circulation patterns, using the Baltic Sea area as a model system. Because information on critical larval traits, such as the pelagic depth distribution, is lacking for virtually all species in the study system, we based our models on data from an extensive fieldsampling program. Simulated data on dispersal and connectivity are then used to analyse the efficiency of the present Natura 2000 network of MPAs in the Baltic Sea. 


\section{MATERIALS AND METHODS}

\section{Study area}

The study area for our numerical experiments of larval dispersal as well as the field sampling program of larval traits is the Baltic Sea, which is a shallow, brackish, intra-continental sea in northern Europe, located between $9^{\circ}$ and $30^{\circ} \mathrm{E}$ and between $54^{\circ}$ and $66^{\circ} \mathrm{N}$ (Fig. 1). The Baltic Sea is the world's second largest brackish sea and consists of a number of subbasins, divided by sills and other morpho- and bathymetrical formations; 3 narrow straits limit water exchange with the Kattegat and the North Sea. Due to their morphology and the proximity to the saline inflow, the sub-basins differ in oceanographic features. The circulation is to a large extent topographically bound in all basins, and the salinity varies from

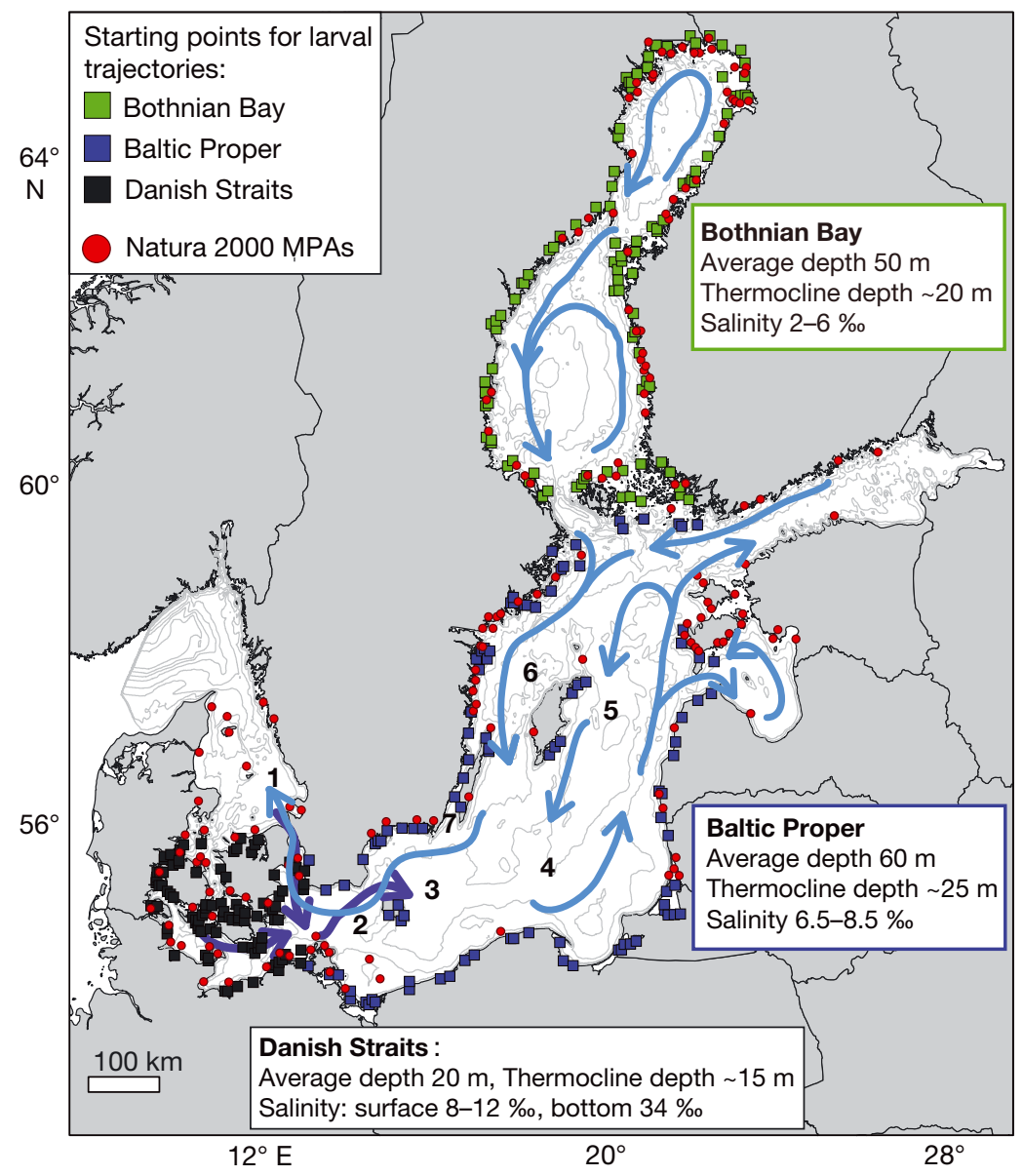

Fig. 1. The study area. Squares: start positions for the larval trajectories; numbers 1 to 7 : field sites where the plankton survey collected monthly samples for $1 \mathrm{yr}$; red circles: centre position of the 161 MPAs in the Baltic Sea and Kattegat with a mean depth of $\leq 12 \mathrm{~m}$. The light and dark blue arrows are surface circulation and saline inflow, respectively, taken from Elken \& Matthäus (2008; their

Fig. A7). Oceanographic data are from Leppäranta \& Myrberg (2009) brackish to almost fresh (Fig. 1). The seasonal thermocline is far more influential for the overall environment than the halocline. The thermocline varies between 15 and $25 \mathrm{~m}$ in summer and is deeper and weaker in winter. The halocline depth is between 40 and $80 \mathrm{~m}$ in most basins, apart from the Danish straits and in Kattegat, where the thermocline and the halocline coincide at $15 \mathrm{~m}$ depth in the summer (Leppäranta \& Myrberg 2009). The Baltic tides are very small $(<10 \mathrm{~cm})$ and can be neglected in all parts of the sea except the Danish Straits (Magaard \& Rheinheimer 1974).

In this study, the Baltic Sea is divided into 3 regions based on distribution of species, circulation patterns and regional climate. Because of the salinity gradient, the distribution of many organisms ends at the border of these regions. The biodiversity decreases from the marine-species-dominated Danish Straits, through the Baltic Proper, with brackish and marine species, to the Gulf of Bothnia, where the fauna is dominated by freshwater species.

The Gulf of Bothnia is strongly influenced by a large freshwater runoff causing a distinct north-south gradient in salinity from $2-4 \%$ in the northern part to $6 \%$ in the southern part. The Baltic Proper, containing more than half of the Baltic Sea water mass, has a surface water salinity varying between 6.5 and 8.5\%. The Danish Straits, consisting of the Belt Sea and the Sound, is a shallow area of furrows between the Danish mainland and islands and the Swedish mainland, where all of the water exchange with the North Sea takes place. The surface water here is the outflow from the Baltic, with salinity between 8 and $12 \%$, and the water below the pycnocline is the inflow water from the Kattegat, with a salinity reaching up to $34 \%$ (Leppäranta \& Myrberg 2009) (Fig. 1).

\section{Larval plankton survey}

Prior to the present study, essentially no information about depth distribution of larvae was available for the Baltic Sea. To obtain empirical data on larval dispersal depth and spawning 
season, samples from an extensive plankton survey were analysed for meroplankton. The main aim of the analysis was to obtain essential information for the parameterization of larval traits in the model. The present study focused on invertebrate and fish larvae for benthic, shallow water species $(<12 \mathrm{~m})$ because a majority of the present Natura 2000 MPAs in the Baltic Sea are located in shallow, coastal waters. The survey, carried out in collaboration with the EU-project BAZOOCA (Baltic zooplankton cascades) and the Swedish Meteorological and Hydrological Institute, consisted of 13 separate $5 \mathrm{~d}$ cruises from 11 May 2009 to 16 April 2010, sampling 7 sites from Anholt in the Kattegat to the Island of Gotland in the Baltic Proper (Fig. 1, Table 1). At each site, plankton samples were taken from 5 discrete depths, ranging from close to the bottom up to the surface, using a multinet plankton sampler (type Midi; Hydro-bios) with a $0.5 \times$ $0.5 \mathrm{~m}$ opening fitted with 5 separate nets equipped with $300 \mu \mathrm{m}$ mesh. The maximal depth at the sites varied from $\sim 20 \mathrm{~m}$ at Site 7 to $>200 \mathrm{~m}$ at Sites 5 and 6, and the depth strata sampled with the 5 nets varied according to the depth at each site, with the exception of the 2 most shallow nets that sampled 0-10 $\mathrm{m}$ and 10-20 m depth at all sites (Table 1). Samples were taken at all $24 \mathrm{~h}$ of the day, including both day- and night-time sampling. The samples were immediately fixed in formaldehyde and later transferred to ethanol before identification and measurement under a stereo-microscope. All identifications of fish larvae were carried out by the Swedish Board of Fisheries at Lysekil, and invertebrate larvae were identified at the Department of Marine Ecology, University of Gothenburg. Marine taxa that were only found at Site 1 in Kattegat were not included in the analysis.

Because vertical movements by larvae on diel schedules are a common phenomenon in nature (Forward 1988, Queiroga \& Blanton 2005) that may affect

Table 1. Sampling depth ranges of the multinet's 5 nets at the 7 sampling sites of the plankton survey. The 5 th net closed at the surface. The 13 cruises were carried out approximately every 4 wk between 11 May 2009 and 16 April 2010

\begin{tabular}{|lcccccc|}
\hline \multirow{2}{*}{$\begin{array}{l}\text { Site } \\
\text { no. }\end{array}$} & Site name & \multicolumn{5}{c|}{$\begin{array}{c}\text { Approximate opening } \\
\text { depth of each net (m) }\end{array}$} \\
& & 1 & 2 & 3 & 4 & 5 \\
\hline 1 & SO Anholt & - & 40 & 30 & 20 & 10 \\
2 & N Arkona & - & 40 & 30 & 20 & 10 \\
3 & Bornholm Deep & 75 & 50 & 30 & 20 & 10 \\
4 & N Gulf of Danzig & 75 & 50 & 30 & 20 & 10 \\
5 & Gotland Deep & 200 & 90 & 50 & 20 & 10 \\
6 & NW Gotland & 180 & 90 & 50 & 20 & 10 \\
7 & Kalmar Sound & - & - & - & - & 10 \\
\hline
\end{tabular}

larval dispersal (Shanks 1995), we initially carried out an analysis of the effect of light intensity on the vertical distribution of larvae to assess if diel vertical migration behaviour should be included in the model. To obtain an estimate of the surface light intensity during each multinet tow, we calculated the cosine of the solar zenith angle at each sample site and time, using the NOAA's Solar Position Calculator (www.srrb.noaa.gov/highlights/sunrise/azel.html). This estimate is an approximation of the vertical component of direct sunlight shining on the horizontal surface at the sample sites and was used as the independent variable in a series of linear regression analyses using the mean depth of each dominant larval taxa per multinet tow as the dependent variable. Multinet tows that did not collect any larvae of the targeted species were excluded from the analysis. We did not assess the effect of tides on the vertical distribution of larvae because of the negligible tidal effects on ocean circulation in the Baltic Sea and because larvae from the Swedish west coast do not appear to migrate in phase with local tides (Queiroga et al. 2002).

To test if the depth distribution of larvae differed significantly from a random pattern, 1-factor ANOVA models were carried out on the most abundant taxa, using sampling depth (net samples 1 to 5) as fixed independent variables and the samples from all sites and dates as replicates (46 to 84 replicates dependent on sampling depth). Prior to the analyses, data were tested for homoscedasticity with Cochran's $C$ test (Underwood 1996) and square root transformed if found heteroscedastic before the ANOVAs were performed. A posteriori multiple comparisons were carried out with the Student-Newman-Keuls (SNK) procedure.

\section{The hydrodynamic model}

To explore the dispersal of planktonic larvae in the present experiment, 2 different computer models were used. First, an ocean circulation model produced fields of velocity, density, salinity and temperature to describe the environment in all parts of the model domain for the modelled time period. Second, an off-line trajectory model calculated the individual paths of the larvae.

The ocean transport data were produced with the Rossby Centre Ocean circulation model (RCO). The $\mathrm{RCO}$ is a Bryan-Cox-Semtner hydrodynamic 3D ocean model for the Baltic Sea and Kattegat in which the conservation equations for momentum, mass, potential temperature and salinity are discretised in 
spherical coordinates and solved on an Arakawa Bgrid (Meier 1999, Meier et al. 2003). The spatial resolution is 2 nautical miles $(3.7 \mathrm{~km})$ in the horizontal and 41 levels in the vertical, ranging from $3 \mathrm{~m}$ at the surface to $12 \mathrm{~m}$ in the deepest parts. The model depths are based on a realistic bathymetry from Seifert \& Kayser (1995). It has an open boundary to the North Sea just south of $58^{\circ} \mathrm{N}$ and is forced by hourly sea level data and climatological mean temperature and salinity profiles from observations. The atmospheric forcing is based on the ERA40 data set, which has been downscaled with the help of a regional atmospheric circulation model to fit the higher resolution grid (Döscher et al. 2002). The accumulated precipitation is added every $12 \mathrm{~h}$, and monthly river runoff data are used. The model has a pseudofree surface, i.e. non-rigid lid approximation sensu Pacanowski \& Griffies (2000), and is coupled with a multi-layer dynamic-thermodynamic ice model of Hibler type (Hibler 1979). A turbulence scheme of the $\kappa-\varepsilon$ type is used to parameterise the subgrid scale mixing (Meier 2001). The RCO model has been thoroughly validated and reproduces velocities, sea surface temperatures, salinity and temperature profiles and ice cover in a satisfactory way (Meier 1999, 2001).

\section{The trajectory model}

To calculate larval trajectories, fields of velocity, density and temperature from the RCO model are saved every $6 \mathrm{~h}$ and then used as input data to the Lagrangian trajectory model TRACMASS (Döös 1995, Blanke \& Raynaud 1997, De Vries \& Döös 2001). TRACMASS makes it possible to determine trajectories both forwards and backwards in time between any sections or regions in the ocean, and the off-line working mode enables calculation of a vast number of trajectories with a small computational cost. The model calculates exact solutions for the trajectory paths for a given stationary velocity field. For a time-dependent field, such as this one, the velocities are assumed to be constant over successive periods less than or equal to the sampling time. Thus, in the present study, the velocity fields are updated every $6 \mathrm{~h}$, but the trajectory calculations are done with a $1 \mathrm{~h}$ time step. The velocities from RCO are given at the sides of each grid box, and to determine the trajectory of a given particle, they are interpolated to the particle's position, and the successive transportation of the particle within the box is calculated analytically. For a technical/mathematical de- scription of the TRACMASS model, see for example Döös (1995). In the present study, only the start and end points of the larval trajectories were saved, but the method enables storing of the full dispersal path of every larva. Although we model the dispersal of larvae, we intend to use this information to infer recruitment of larvae to MPAs. Recruitment encompasses more processes than dispersal, but to simplify the presentation and discussion of results, we use the term recruitment for successful dispersal from a spawning site to a destination site at the end of the trajectory. We also use the term local recruitment to indicate dispersal trajectories from a spawning site or a specific MPA that also end in the same site or MPA.

\section{Experimental design}

The focus group of the present study is organisms residing at shallow depths $(<12 \mathrm{~m})$ after their pelagic larval phase. To assess how their dispersal is affected by different combinations of larval traits and regional differences in circulation, the effects of dispersal depth (swimming/drifting depths), spawning season, pelagic larval duration (PLD), region and year were tested in a fully orthogonal factorial experiment. The larval traits consisted of 4 different spawning seasons - spring (February to April), summer (May to July), autumn (August to October) and winter (November to January), 3 PLDs $(10,20$ and $40 \mathrm{~d})-$ and 3 fixed dispersal depths $(0.5,10$ and $30 \mathrm{~m})$, based on the results of the field survey (Fig. 2). Each of the 36 combinations of larval traits was tested in each of the 3 regions (Gulf of Bothnia, Baltic Proper and Danish Straits) during 2 different years (1989 and 1996), with 216 treatment combinations in total.

For each treatment combination, 49 larval trajectories $(7 \times 7$, evenly spread out within the grid box $)$ were released to be advected by the flow field from each of 100 randomly selected grid boxes with a mean depth of $\leq 12 \mathrm{~m}$ within each of the 3 regions (Fig. 1). The mean net dispersal distance of these 4900 trajectories was used as a dependent variable in the analysis. Replicates were obtained by releasing larval trajectories at 3 separate dates within each spawning season, for each treatment combination $(\mathrm{n}=3)$. In total, $\sim 3.2$ million trajectories were modelled in the whole experiment. Upon release, the larval trajectories moved to the designated dispersal depth as soon as possible. If the bottom depth was smaller than the assigned depth during parts of the dispersal time, the larvae dispersed in the depth layer closest to the bottom. 

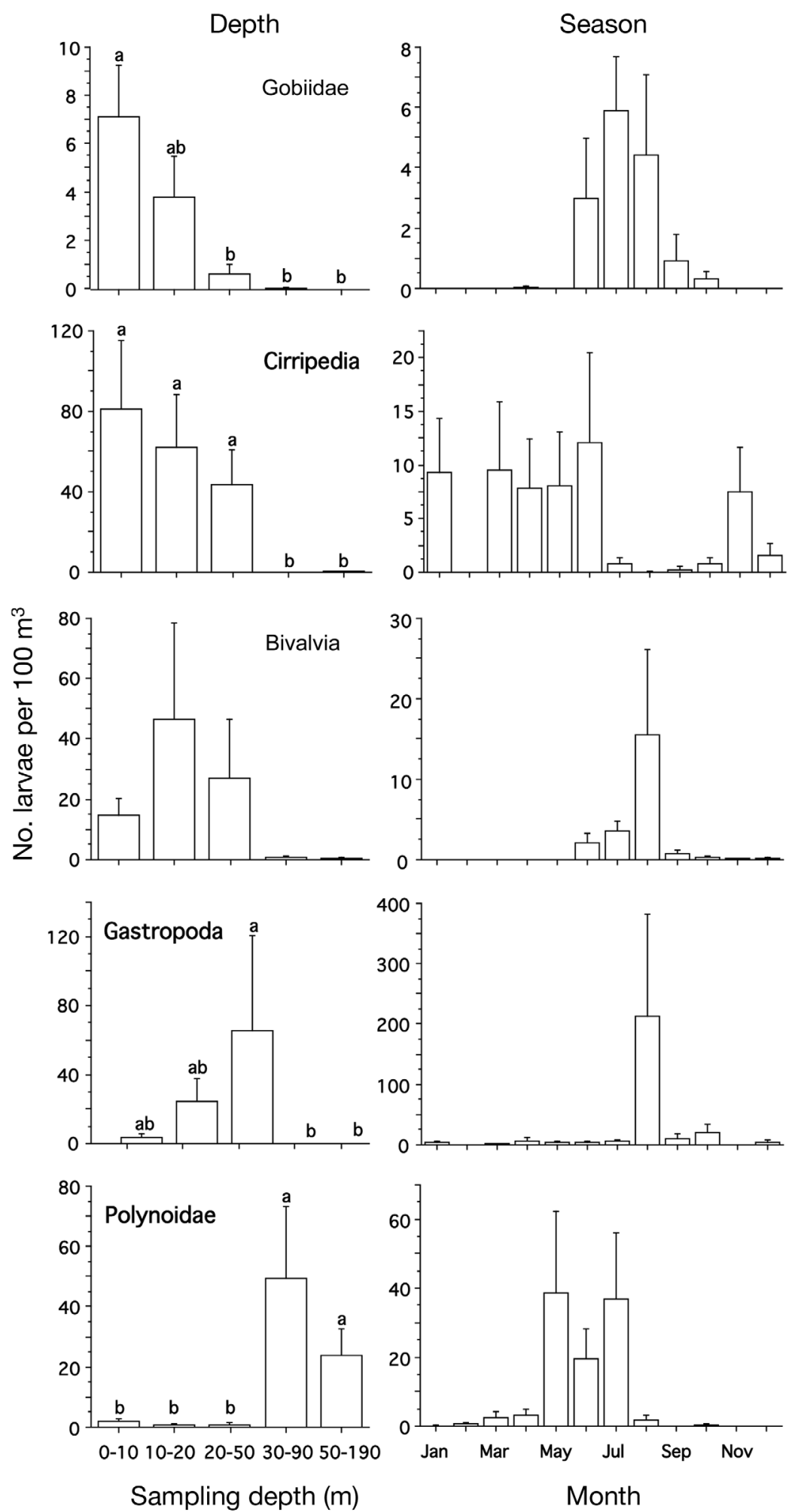

Sampling depth $(\mathrm{m})$

Fig. 2. Mean larval abundance (no. $100 \mathrm{~m}^{-3} ;+1 \mathrm{SE}$ ) of Gobiidae (dominated by benthic Gobiinae species), Cirripedia (both nauplii and cyprid larvae), bivalves, gastropods and scale worms (polynoid polychaetes) as a function of sampling depth (net 1 to $5, \mathrm{n}=46$ to 84 ) and sampling month (January to December, $n=7$ ). Data are pooled from all sites. Different letters above bars indicate significantly different means ( $p<0.05$, SNK test)
The selection of larval traits was based on the results from the plankton survey and the literature (see Table S1 in the supplement at www.int-res.com/ articles/suppl/m467p029_supp.pdf for a summary) to represent the dominant shallow water benthic taxa in the study region. Although the pycnocline differs among regions, the dispersal depth of $10 \mathrm{~m}$ was above the thermocline and the dispersal depth of $30 \mathrm{~m}$ was below the thermocline in all regions. The $0.5 \mathrm{~m}$ dispersal depth was included to represent larval taxa that accumulate close to the surface (see 'Results') and are more subjected to wind-driven circulation. The modelled years, 1989 and 1996, were chosen for representing 2 extremes in the NorthAtlantic oscillation cycle NAO: 1989 had a strong positive anomaly, while 1996 had a strong negative NAO anomaly (Hurrell \& Deser 2009), and thus, their use includes as much climatological variability as possible. The Gulf of Finland, the Gulf of Riga and Kattegat were not included in the areas where larvae were released, but these waters were included in the domain of the circulation model, and the larvae were free to move within these regions if the currents brought them there.

\section{Analysis of data}

To assess the relative importance of dispersal depth, PLD, spawning season, region and year for the dispersal distance of the modelled trajectories, we estimated the magnitude of effects of the variance sources using a 5 -factor analysis of variance (ANOVA), with mean net dispersal distance as dependent variable. Net dispersal distances between the starting and end points of simulated trajectories were calculated from the great-circle distance (Sinnott 1984). Dispersal distance was $\log _{\mathrm{e}}$-transformed prior to analysis. The variance components were calculated according to Under- 
wood (1996), and all effects were normalised to sum to unity.

To explore how the connectivity between sites depended on dispersal depth and geographic location, the pairwise connectivity (number of trajectories released at site $i$ and ending in site $j$ ) was calculated between all pairs of the 300 randomly selected sites (single grid cells) in Fig. 1. The mean pairwise connectivity was normalised against mean local recruitment and plotted against pairwise distance in $1 \mathrm{~km}$ bins. Local recruitment in this case was defined as trajectories starting and ending in the same site (grid cell). Local recruitment obviously depends on the scale that is considered to be local (e.g. Kritzer \& Sale 2004). In the present study, the scale of individual model grid cells $(3.7 \mathrm{~km})$ well matches the median size of Natura 2000 MPAs in the northeast Atlantic $(3 \mathrm{~km})$, in the Baltic Sea $(4 \mathrm{~km})$ and the subset in the shallow Baltic Sea $(7 \mathrm{~km})$. Estimated dispersal distances and scales of local recruitment were compared to the present MPA network in the shallow Baltic Sea within the European Union Natura 2000 network (Fig. 1). The analysis of how the Natura 2000 MPA size matches local recruitment, as estimated from the biophysical model, was compared for each of 152 individual MPA within the area investigated. The required local recruitment for population persistence is poorly known and depends on contextspecific demography in addition to dispersal. In fisheries management, it is often assumed that a persistent population requires that 20 to $50 \%$ of the unfished, life-time production of larvae survives to recruitment (e.g. Mace 1994). For MPAs in a 'scorched earth' scenario (Kaplan et al. 2006), a similar requirement of local recruitment may be assumed. Models using simple dispersal kernels show that local population persistence occurs if the standard deviation of dispersal distance is of the order of MPA width (Kaplan et al. 2006, Botsford et al. 2009), which implies a local recruitment of $\sim 40 \%$ if a Gaussian or Laplacian dispersal distribution is assumed and integrated across the MPA. Where MPAs rely only on local recruitment, we assumed a critical level of $50 \%$ to ensure population persistence. Thus, the median dispersal distance indicates the necessary radius of a circular MPA that allows for $50 \%$ local recruitment. This may be a slight overestimation but is a precautionary choice in the absence of better information about necessary rates of local recruitment. GIS data for all Baltic MPAs were compiled from the HELCOM data source (www.helcom.fi/GIS/en_GB/ HelcomGIS/), and MPA area and nearest neighbour distance (NND) were calculated as centroid to cen- troid distance with ESRI ArcMap. Size of MPAs was estimated as the diameter of the circle with the same area as the MPA polygon.

\section{RESULTS}

\section{Larval plankton survey}

Field samples of invertebrate and fish larvae in the Baltic Proper and in the Kattegat identified 5 taxa of fish and 7 taxa of invertebrates that are common in shallow waters as adults within the study region. Most taxa displayed a distinct larval season and a non-random depth distribution of larvae in which different taxa aggregated at different depth strata (for a summary, see Table S1 in the supplement). We found little support of diel vertical migration or ontogenetic shifts in depth distribution among the collected taxa, suggesting that their dispersal could be accurately modelled using fixed larval depths.

The correlation between the estimated light intensity and the vertical distribution of larvae was very low for 6 of the 7 taxa that were abundant enough to assess statistically ( $\mathrm{p}>0.25 ; \mathrm{r}^{2}<0.09$ for all taxa; Table 2, Fig. S1 in the supplement). The only exception was for bryozoan larvae that showed a significant positive correlation between depth and light intensity, indicating a nocturnal diel vertical migration. For all other taxa, the lack of correlation suggests that diel vertical movements should not affect dispersal and could be excluded from the model. In Cirripedia, we initially analysed nauplii and cyprid

Table 2. Light dependent distribution of planktonic larvae. Simple linear regression analyses using the mean depth distribution (average depth per multinet sample) of benthic gobids (Gobiinae), Cirripedia (nauplii and cyprid larvae), bivalves, gastropods, spionid and polynoid polychaetes and bryozoans as a function of estimated light intensity (mean cosine solar zenith angle per multinet sample) using data from multinet samples where the larval type was present. SS: sums of squares of the regression in the linear regression analyses. Significant values $(p<0.05)$ in bold

\begin{tabular}{|lccccc|}
\hline Dependent variable & df & SS & $F$ & $p$ & $\mathrm{r}^{2}$ \\
\hline Gobiinae & 1,16 & 250 & 1.10 & 0.310 & 0.064 \\
Cirripedia nauplii & 1,17 & 22 & 0.33 & 0.575 & 0.021 \\
Cirripedia cyprids & 1,19 & 61 & 0.14 & 0.71 & 0.008 \\
Bivalvia & 1,24 & 944 & 1.37 & 0.251 & 0.054 \\
Gastropoda & 1,12 & 2163 & 1.17 & 0.301 & 0.089 \\
Spionidae & 1,19 & 26 & 0.09 & 0.763 & 0.005 \\
Polynoidae & 1,24 & 1871 & 0.75 & 0.396 & 0.030 \\
Bryozoa & 1,5 & 180 & 14.0 & $\mathbf{0 . 0 1 3}$ & $\mathbf{0 . 7 4}$ \\
\hline
\end{tabular}


larvae in a 2-factor ANOVA, using depth and larval stage as independent variables to assess if depth distribution changed during ontogeny. The depth distribution of nauplii and cyprid larvae did not differ, as the depth $\times$ larval stage interaction effect was not significant $(\mathrm{df}=4,634 ; F=0.55 ; \mathrm{p}=0.70)$, suggesting that the larval stages could be analysed together. Both larval stages showed a similar depth distribution, with a large majority of larvae above the pycnoclines, and the average depth of cyprid larvae $(15 \mathrm{~m})$ was slightly deeper than that for nauplii larvae $(12 \mathrm{~m})$. Neither larval stage changed depth distribution in response to the light intensity (Table 2).

Five families of fish larvae were identified: gobids (Gobiinae), cottids (Cottidae), pipefish (Syngnathinae), liparids (Liparidae) and the rock gunnel Pholis gunnelus L. (Pholidae), which showed distinct patterns in swimming depth and recruitment periods. Benthic gobid larvae (cf. Pomatoschistus spp. and Gobius niger L.), which were the only fish taxon abundant enough to assess statistically, were significantly more abundant close to the surface $(0-10 \mathrm{~m}$ depth) than below $20 \mathrm{~m}$ depth. They also showed a clear larval recruitment period during the summer months, with a peak in June to August (Table 3, Fig. 2). Similarly, the straight-nose pipe fish Nerophis ophidion L. was also found only during the summer months and exclusively in the top $10 \mathrm{~m}$ of the water column. In contrast, the larvae of the rock gunnel and the seasnail Liparis spp. were found during winter and spring months and were most abundant at the 10-30 $\mathrm{m}$ and 20-50 $\mathrm{m}$ depths, respectively (see Table S1 in the supplement).

Most invertebrate taxa assessed also showed a non-random larval depth distribution in which different taxa aggregated at different depth strata. The depth distribution of bryozoan larvae was similar to that of gobid fish larvae, with $94 \%$ of the larvae above $20 \mathrm{~m}$ depth. However, no significant difference was found among sampling depths (Table 3). The abundance of unidentified Cirripedia larvae, likely dominated by the acorn barnacle Balanus improvisus Darwin (nauplii and cyprid larvae analysed together), also decreased with depth, with significantly higher densities at 0-30 $\mathrm{m}$ compared to deeper samples (Fig. 2, Table 3). Larvae of unidentified bivalves (likely dominated by the blue mussel Mytilus edulis/trossulus L./Gould) and spionid polychaete larvae (Spionidae) showed high abundance in the top $30 \mathrm{~m}$ of the water column, with highest abundance around $20 \mathrm{~m}$ depth and very few larvae below $40 \mathrm{~m}$ (Fig. 2). Both taxa showed a significant effect of sampling depth (Table 3), but the SNK test only detected a significant difference between means for the spionids, which showed significantly higher abundance at 20-30 m depth compared to deeper sampling depths. The abundance of unidentified gastropod larvae increased from the surface down to 20-30 m depth, where the abundance was significantly higher compared to deeper sampling depths (Fig. 2, Table 3). In contrast, the larval abundance of polychaete scale worms (Polynoidae) showed significantly higher abundance at 30-190 m depth compared to the shallower sampling depth (Fig. 2, Table 3). The larval abundance of most invertebrate taxa showed distinct seasonal patterns. Spionid polychaetes showed highest abundance in winter and early spring (January to May), scale worms were most abundant in early summer (May to July), bivalves and gastropods showed a distinct peak in abundance in late summer (August), and bryozoans peaked in mid-winter (November to January). Nauplii and cyprid larvae of Cirripedia were present during most months, with a dip in abundance during the summer months (June to September). The extended recruitment period for Cirripedia may indicate that more than one dominant species was included in the group (Fig. 2).

The main aim of the plankton survey was to assess the average vertical distribution of different larval taxa. The low abundance of larvae at many stations and sampling times prevented analyses of the interactive effect between depth and station and sampling time, which may have obscured regional

Table 3. Depth distribution of planktonic larvae. One-factor ANOVA models testing the larval abundance (no. $\mathrm{m}^{-3}$ ) of benthic gobids (Gobiinae), bryozoans, barnacles (Cirripedia), bivalves, gastropods and spionid and polynoid polychaetes as a function of sampling depth (nets 1 to 5) using data from all cruises and stations ( $\mathrm{df}=4,317$ in all tests). The number of replicates varied from 46 for the deepest sampling strata $(50-190 \mathrm{~m})$ to 84 replicates for the shallowest strata $(0-10 \mathrm{~m})$. SS: sums of squares of the factor sampling depth. All data was sqrt(sqrt(x))-transformed to meet assumptions of homogenous variance. Significant values in bold

\begin{tabular}{|lccc|}
\hline Dependent variable & SS & $F$ & $\mathrm{p}$ \\
\hline Gobiinae & 8.64 & 3.72 & $\mathbf{0 . 0 0 2}$ \\
Bryozoa & 0.363 & 1.85 & 0.119 \\
Cirripedia & 2.75 & 4.14 & $\mathbf{0 . 0 0 3}$ \\
Bivalvia & 0.981 & 2.44 & $\mathbf{0 . 0 4 7}$ \\
Spionidae & 0.706 & 2.59 & $\mathbf{0 . 0 3 7}$ \\
Gastropoda & 1.11 & 3.57 & $\mathbf{0 . 0 0 7}$ \\
Polynoidae & 2.07 & 7.18 & $\mathbf{0 . 0 0 0 1}$ \\
\hline
\end{tabular}


and temporal variation in depth distribution. However, although certain taxa were more abundant at certain stations (e.g. bryozoa and gastropods were more abundant at Stn 1; polynoid polychaetes were more abundant at Stns 4 to 7 ), the vertical distribution of each taxa was very consistent among stations, suggesting that this problem was minor. Still, it is important to note that the present study was not designed to assess vertical migration on diel or ontogenetic schedules, and the pooling of data across sampling times and sites may have decreased our ability to detect vertical migration in the larvae. The low taxonomic resolution of the Cirripedia larvae may also have prevented us from detecting ontogenetic changes. Thus, more studies are needed before any conclusion can be drawn regarding the prevalence of vertical migration among larvae in the Baltic Sea.

\section{Analysis of existing MPAs in the Baltic Sea}

In order to compare critical MPA size and spacing based on our simulations of larval dispersal and local recruitment, we compiled information from the existing Natura 2000 MPA network in the Baltic Sea. There are 161 MPAs in the HELCOM area that include shallow waters (mean depth $\leq 12$ $\mathrm{m})$, and 152 MPAs are within the area that we included in the dispersal experiments. The centroid positions of all of these are shown in Fig. 1, and their size, assumed to be circular, is shown in Fig. 3. The mean diameter of the MPAs is $10.9 \mathrm{~km}$, and $50 \%$ of the MPAs are $<8 \mathrm{~km}$ in diameter, while $90 \%$ are $<22 \mathrm{~km}$. The mean centroid NND for the Baltic Sea MPAs is $24 \mathrm{~km}, 50 \%$ of the NND are $<17 \mathrm{~km}$, and $90 \%$ are $<40 \mathrm{~km}$. We also calculated the mean distance that includes 5 neighbouring MPAs, which is $63 \mathrm{~km}$.

\section{Dispersal distance and MPA size}

The multi-factorial design of the present study allowed a formal test of how the modelled dispersal distance depended on the tested factors, i.e. dispersal depth, PLD, spawning season, region and annual variation in regional climate. A comparison of the relative magnitude of effects showed that dispersal depth and PLD together accounted for as much as $78 \%$ of the explained variation, whereas seasonal, annual and regional variation had surprisingly small effects on dispersal distance (Table 4).

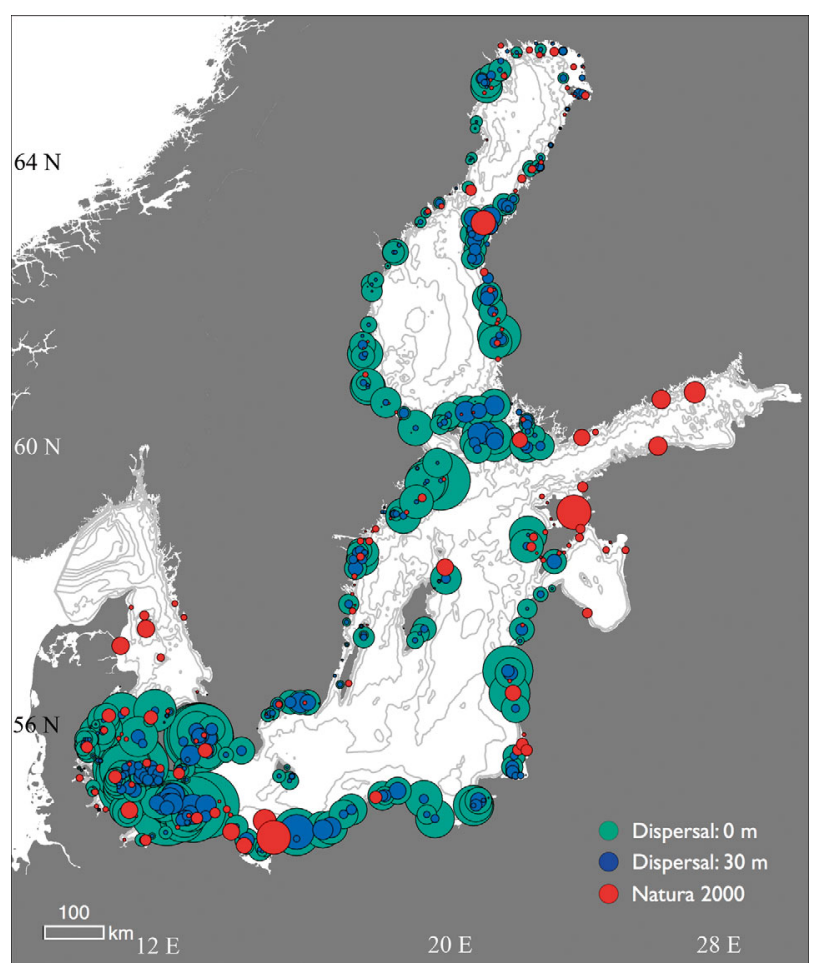

Fig. 3. Median dispersal distance, plotted as radius, for a larva in summer/autumn with a pelagic larval phase of $20 \mathrm{~d}$, swimming at the surface (green) and at $30 \mathrm{~m}$ (blue). The figure highlights the regional variation in dispersal pattern. Also shown is the network of shallow MPAs within the Natura 2000, where the circle diameters indicate the size of individual MPAs (assumed to be circular)

Mean dispersal averaged over regions and time ranged from 10 to $70 \mathrm{~km}$. The distances increased with PLD and decreased with swimming depth, with the greatest reduction from the surface to $10 \mathrm{~m}$ (Fig. 4, Table 5). The small difference between 10 and $30 \mathrm{~m}$ depth may partly be explained by the bathymetry, as many trajectories during part of the dispersal traversed shallow areas with maximum depths $<30 \mathrm{~m}$, especially in the relatively shallow Danish Straits region. The effect of PLD was stronger on larvae dispersing close to the surface compared to larvae at deeper depths. This effect was largely consistent across seasons, years and regions, although there were slightly larger seasonal differences for longer PLDs in the Baltic Proper and Gulf of Bothnia (Fig. 4, Table 4).

Spawning season, region and year had, in contrast to PLD and dispersal depth, surprisingly small effects on the dispersal distance and together explained $<9 \%$ of the variability in the data as single factors (Table 4). The 2 -factor interaction between season and region explained $\sim 5 \%$ of the variability and was 
Table 4. Effect of pelagic larval duration (PLD), dispersal depth, spawning season, region (basin) and year on the dispersal distance. Multifactorial ANOVA. The relative effects in \% are from the magnitude of effects calculated according to Underwood (1996)

\begin{tabular}{|c|c|c|c|}
\hline Sources & df & MS & $\begin{array}{l}\text { Relative } \\
\text { effects (\%) }\end{array}$ \\
\hline PLD & 2 & 43.1 & 41.8 \\
\hline Depth & 2 & 36.7 & 35.6 \\
\hline Season & 3 & 3.05 & 4.3 \\
\hline Region & 2 & 2.53 & 2.4 \\
\hline Year & 1 & 3.25 & 1.5 \\
\hline PLD $\times$ Depth & 4 & 0.41 & 0.6 \\
\hline PLD $\times$ Season & 6 & 0.29 & 0.6 \\
\hline PLD $\times$ Region & 4 & 0.14 & $<0.1$ \\
\hline PLD $\times$ Year & 2 & 0.19 & $<0.1$ \\
\hline Depth $\times$ Season & 6 & 0.072 & $<0.1$ \\
\hline Depth $\times$ Region & 4 & 0.07 & $<0.1$ \\
\hline Depth $\times$ Year & 2 & 0.018 & $<0.1$ \\
\hline Season $\times$ Region & 6 & 1.78 & 4.9 \\
\hline Season $\times$ Year & 3 & 4.78 & 6.8 \\
\hline Region $\times$ Year & 2 & 0.27 & $<0.1$ \\
\hline PLD $\times$ Depth $\times$ Season & 12 & 0.026 & $<0.1$ \\
\hline PLD $\times$ Depth $\times$ Region & 8 & 0.022 & $<0.1$ \\
\hline PLD $\times$ Depth $\times$ Year & 4 & 0.01 & $<0.1$ \\
\hline PLD $\times$ Season $\times$ Region & 12 & 0.042 & $<0.1$ \\
\hline PLD $\times$ Season $\times$ Year & 6 & 0.099 & $<0.1$ \\
\hline PLD $\times$ Region $\times$ Year & 4 & 0.062 & $<0.1$ \\
\hline Depth $\times$ Season $\times$ Region & 12 & 0.012 & $<0.1$ \\
\hline Depth $\times$ Season $\times$ Year & 6 & 0.45 & $<0.1$ \\
\hline Depth $\times$ Region $\times$ Year & 4 & 0.009 & $<0.1$ \\
\hline Season $\times$ Region $\times$ Year & 6 & 0.64 & 1.6 \\
\hline PLD $\times$ Depth $\times$ Season $\times$ Region & 24 & 0.007 & $<0.1$ \\
\hline PLD $\times$ Depth $\times$ Season $\times$ Year & 12 & 0.01 & $<0.1$ \\
\hline PLD $\times$ Depth $\times$ Region $\times$ Year & 8 & 0.026 & $<0.1$ \\
\hline PLD $\times$ Season $\times$ Region $\times$ Year & 12 & 0.066 & $<0.1$ \\
\hline Depth $\times$ Season $\times$ Region $\times$ Year & 12 & 0.018 & $<0.1$ \\
\hline \multicolumn{4}{|l|}{ PLD $\times$ Depth $\times$ Season $\times$ Region } \\
\hline$\times$ Year & 24 & 0.01 & $<0.1$ \\
\hline Residual & 432 & 0.098 & \\
\hline
\end{tabular}

Table 5. Dispersal distance (50th and 90th percentiles) for all combinations of dispersal depth and planktonic larval duration. Values are averaged over areas, years, seasons and times within season $(n=352800)$. (The data are also shown graphically in Fig. 5B for a selection of the combinations)

\begin{tabular}{|lcc|}
\hline \multirow{2}{*}{ Depth and PLD } & \multicolumn{3}{c|}{ Dispersal distance $(\mathrm{km})$} \\
& $50 \%$ & $90 \%$ \\
\hline 10 d surface & 15.9 & 64.3 \\
10 d $10 \mathrm{~m}$ & 7.6 & 34.1 \\
10 d 30 m & 7.9 & 30.4 \\
20 d surface & 27.8 & 100.8 \\
20 d $10 \mathrm{~m}$ & 11.6 & 54.6 \\
20 d 30 m & 11.3 & 43.5 \\
40 d surface & 46.2 & 161.4 \\
40 d $10 \mathrm{~m}$ & 17.0 & 87.0 \\
40 d 30 m & 15.9 & 64.5 \\
\hline
\end{tabular}

caused by longer trajectories in the Danish Straits in the spring and summer, while trajectories were longer in the Baltic regions in the autumn and winter (Fig. 4, Table 4). An interaction effect between season and year accounted for $\sim 7 \%$ of the variation in dispersal distance and was possibly caused by the autumn of 1996 being more windy, leading to longer dispersal distances that year.

Fig. 5 shows the frequency distributions for selected combinations of PLD and dispersal depth and reveals a marked skew toward longer distances. In surface waters, $\sim 50 \%$ of all larvae with a PLD of $40 \mathrm{~d}$ dispersed $>45 \mathrm{~km}$, and $10 \%$ dispersed $>160 \mathrm{~km}$. At the other end of the scale, with dispersal at $30 \mathrm{~m}$ and a PLD of $10 \mathrm{~d}$, only $10 \%$ of all larvae dispersed $>30 \mathrm{~km}$, and $50 \%$ dispersed $<8 \mathrm{~km}$ (Fig. 5). Note that larvae dispersing $40 \mathrm{~d}$ at $30 \mathrm{~m}$ depth showed about the same cumulative dispersal frequency distribution as larvae dispersing in surface waters for $10 \mathrm{~d}$. This is a pronounced reduction of the dispersal distance for the 40 d larvae; changing drifting depth from the surface to $30 \mathrm{~m}$ is comparable to a reduction in PLD of $30 \mathrm{~d}(75 \%)$, in this case. Although dispersal distance differed little among the 3 regions, the variability on smaller spatial scales was larger, as seen from Fig. 3.

Assuming that an MPA is circular and that dispersal starts from the centre, the median dispersal distance for different combinations of dispersal depths and PLDs approximates the radius of a MPA that receives $50 \%$ local recruitment for that larval type. Table 5 shows the dispersal distances expected for 50 and $90 \%$ of all released larvae as a function of PLD and drift depth. If the origin is placed within a circular MPA, Table 5 indicates that for $50 \%$ local recruitment to occur, the MPA has to be at least 15 to $92 \mathrm{~km}$ in diameter, depending on dispersal depth and PLD. A summary of local recruitment as a function of MPA size for all combinations of dispersal depth and PLD is given in Fig. S2 in the supplement. Plotting the median dispersal distances for each release site and the size of the present MPAs in the study area on the same scale shows that local oceanographic conditions and dispersal distances also have a large influence on the degree of local recruitment of an MPA (Fig. 3). Fig. 6 more clearly shows how the majority of individual MPAs in the Natura 2000 network are smaller than the local median dispersal distance. Only in the Danish Straits for the most stationary larval traits (PLD: $10 \mathrm{~d}$, drift depth: $30 \mathrm{~m}$ ) were most of the MPA sufficiently large. In the Gulf of Bothnia, MPAs were generally far too small compared to local dispersal distance. 

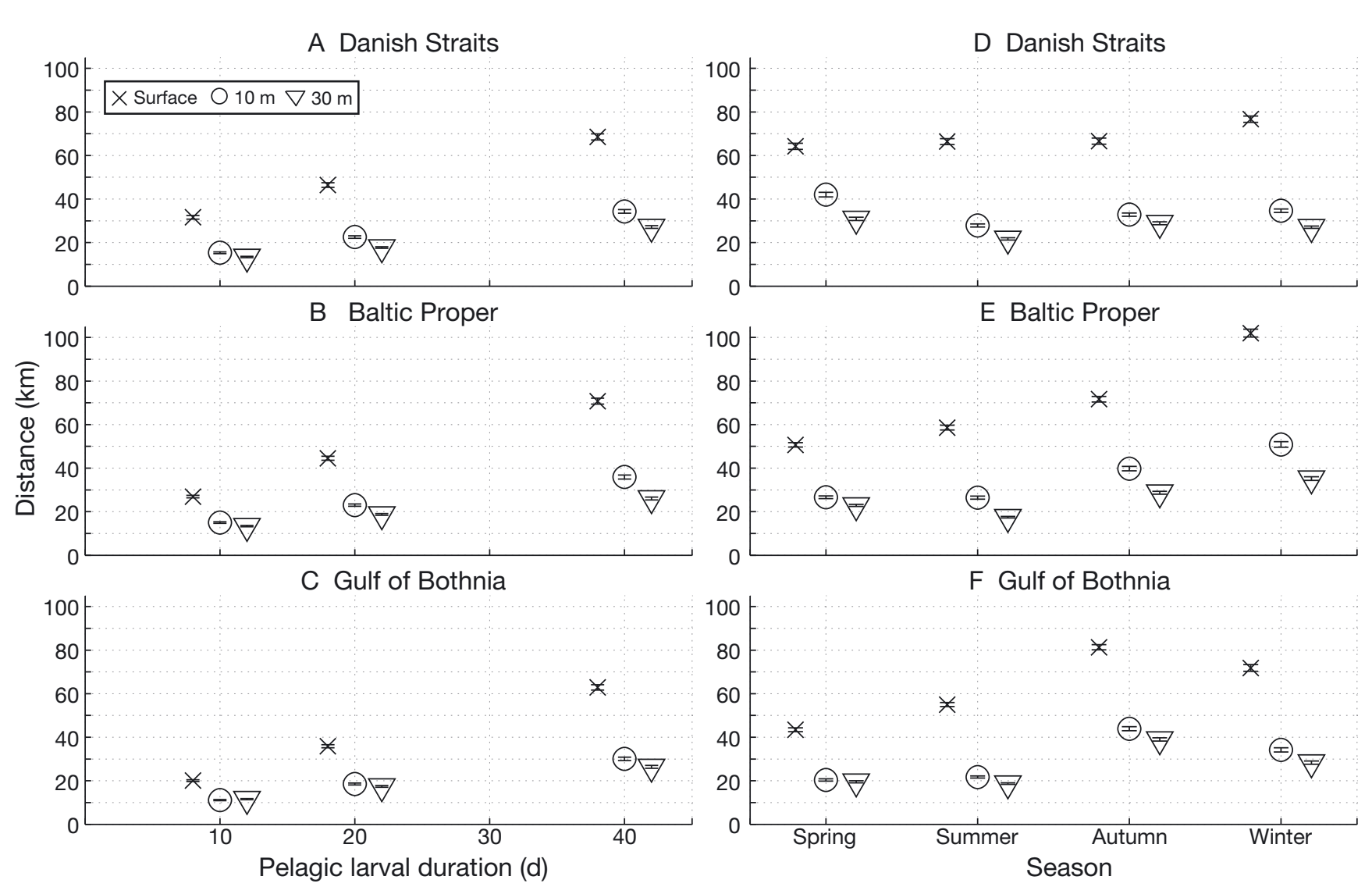

Fig. 4. Mean dispersal distance in $\mathrm{km}( \pm 1 \mathrm{SE}, \mathrm{n}=2400)$ as a function of $(\mathrm{A}-\mathrm{C})$ pelagic larval duration (PLD) and dispersal depth for the 3 regions and (D-F) season and dispersal depth for the 3 regions for $40 \mathrm{~d}$ PLD. The markers are slightly shifted horizontally for clarity. Note that the SE bars are all within the scale of the markers

\section{Dispersal direction}

As expected, the direction of the modelled dispersal was constrained by bathymetry and the general cyclonic circulation in the regions (seen in Fig. 1), particularly along the Swedish and Finnish coasts in the Gulf of Bothnia. Because we used a mean value of dispersal from 100 sites within each region and modelled basins rather than a straight coastline, the mean dispersal direction within each region provided limited information of treatment effects on the spread of larvae in the constrained regions. However, plotting the end points of each trajectory and colour-coding them after the net direction travelled revealed dramatic effects of larval swimming depth on both dispersal direction and the resulting distribution of larvae (Fig. 7). In the Danish Straits, a majority of the larvae dispersing in surface waters received a strong northward transport (on average, $41 \mathrm{~km}$ north in $40 \mathrm{~d}$ ), whereas a large proportion of the larvae swimming at $10 \mathrm{~m}$ or deeper followed the saline inflow in a south-easterly direction. This depth-specific dispersal in the Danish Straits was consistent over seasons and years. In the

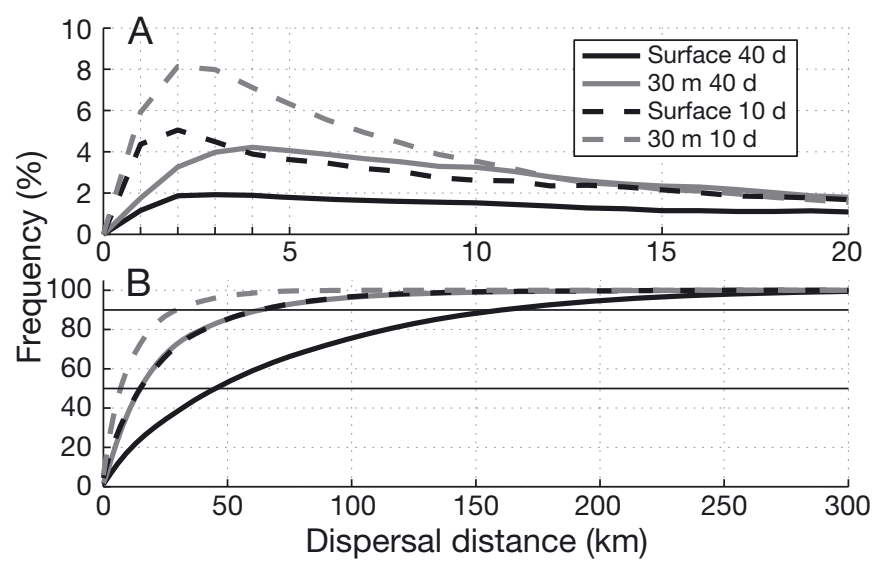

Fig. 5. (A) Frequency of larvae (\%) plotted against dispersal distance and (B) cumulative frequency of dispersal distances. The horizontal lines mark the $50 \%$ and $90 \%$ cumulative frequency. The larval trajectories are sorted in $1 \mathrm{~km}$ bins but for clarity are plotted as continuous curves

Baltic Proper and in the Gulf of Bothnia, swimming depth had a strong effect on cross-shelf transport and the distribution of larvae. Surface swimming larvae were transported more offshore, resulting in a wider 


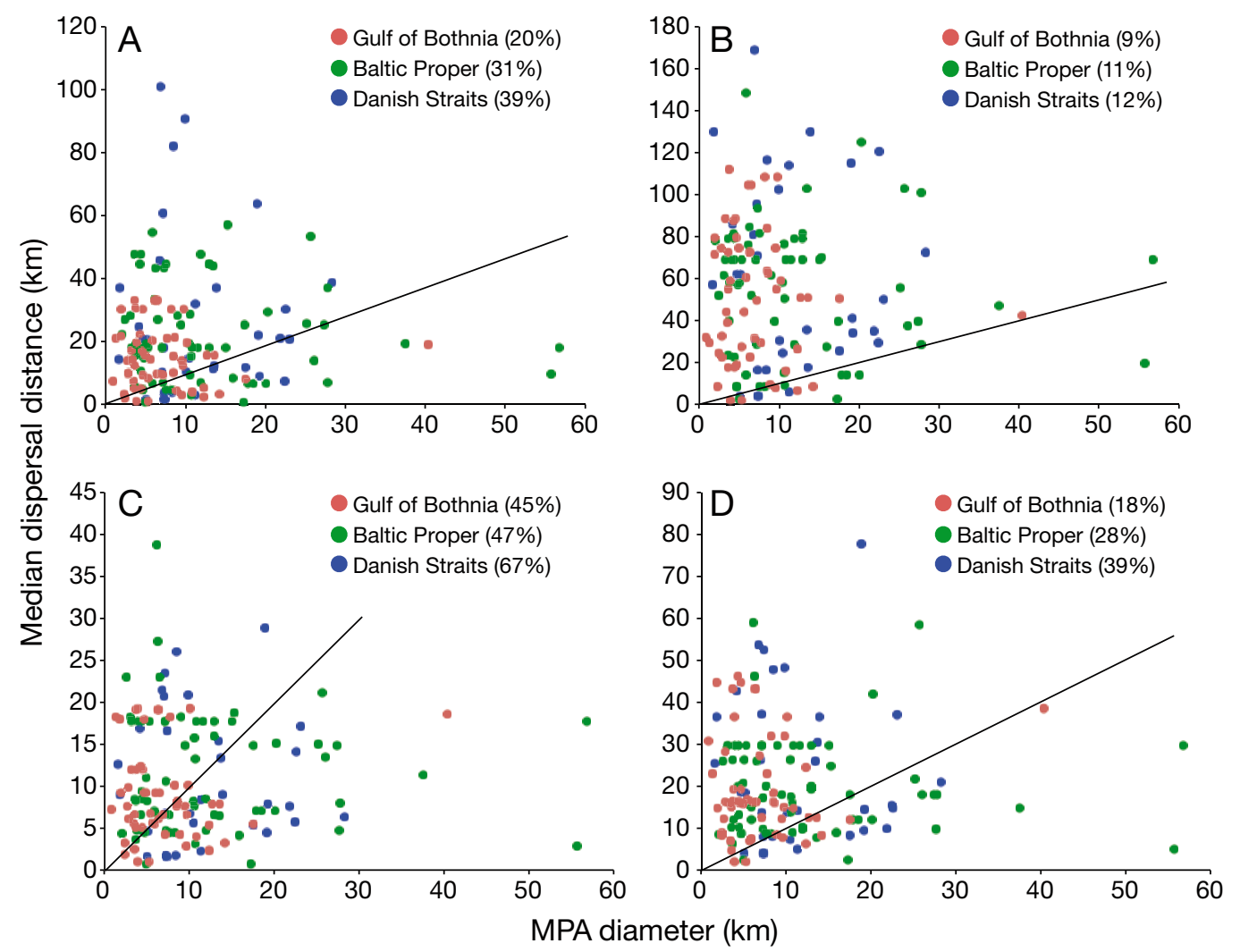

Fig. 6. Size of 152 MPAs within the Natura 2000 network plotted against the median of local dispersal distance, estimated by the biophysical model. Size is given as the diameter of a circle with the same area as each MPA. Median dispersal distance represents $50 \%$ local recruitment in each MPA, and the line indicates where MPA size and median dispersal distance are equal. Colours show location of each MPA. The panels show 4 combinations of PLD and larval drift depth. (A) PLD: $10 \mathrm{~d}$, drift depth: 0 m. (B) PLD: 40 d, drift depth: 0 m. (C) PLD: 10 d, drift depth: $30 \mathrm{~m}$. (D) PLD: 40 d, drift depth: $30 \mathrm{~m}$. Also shown are the percentages of MPA larger than median dispersal distance for the Gulf of Bothnia, the Baltic Proper and the Danish Straits, respectively

distribution of larvae compared to larvae swimming at $30 \mathrm{~m}$ depth, which remained close to the coastline (Fig. 7). Note that the larvae at $30 \mathrm{~m}$ depth dispersed $25 \mathrm{~km}$ on average (Fig. 4B,C), so the coastal retention is an effect of along-shore travel and not of larvae being stuck at their release site. Thus, coastal retention increased with swimming depth in all regions.

\section{Analysis of connectivity}

Fig. 8 shows how the pairwise inter-site connectivity between the 300 starting positions for the larval trajectories declines with distance for 4 combinations of dispersal depth $(0$ and $30 \mathrm{~m})$ and PLD (10 and $40 \mathrm{~d})$. The median NND for the 300 sites was $8 \mathrm{~km}$. The connectivity rapidly declines with distance and was generally $<1 \%$ of local recruitment beyond a distance of $50 \mathrm{~km}$. The exception was for a PLD of $40 \mathrm{~d}$ in surface waters, where the tail was much fatter and showed connectivities above $5 \%$ of local recruitment (intra-site connectivity) even at a distance of $50 \mathrm{~km}$. The rate of decline increased with dispersal depth.

\section{DISCUSSION}

Possingham \& Roughgarden (1990) previously pointed out that populations of marine sessile invertebrates face the risk of local extinction if their planktonic larvae are continuously advected down-stream by along-shore currents. Advection and turbulent diffusion leading to reduced local recruitment can also be a serious functional constraint when designing MPAs (Roberts 1997). Gaines et al. (2003) concluded that the location of MPAs in relation to spatial and temporal variation in ocean circulation patterns should determine the recruitment success and longterm persistence of marine sessile populations with 


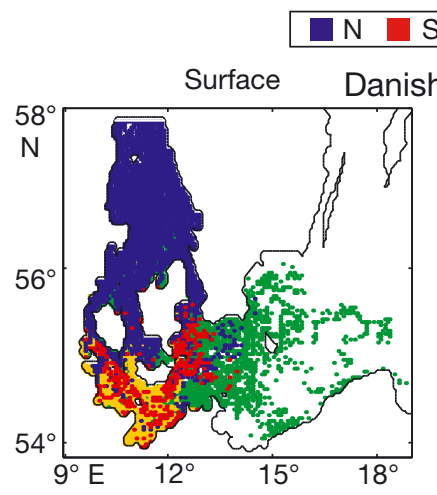

$S \square E-W$

\section{Straits 30 meters}

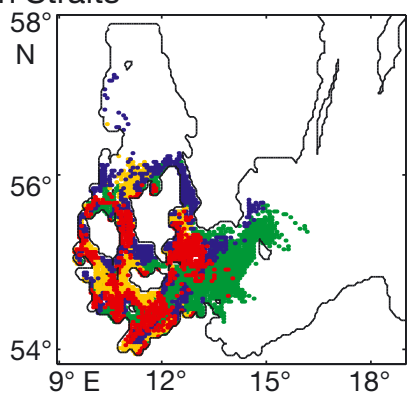

Baltic Proper
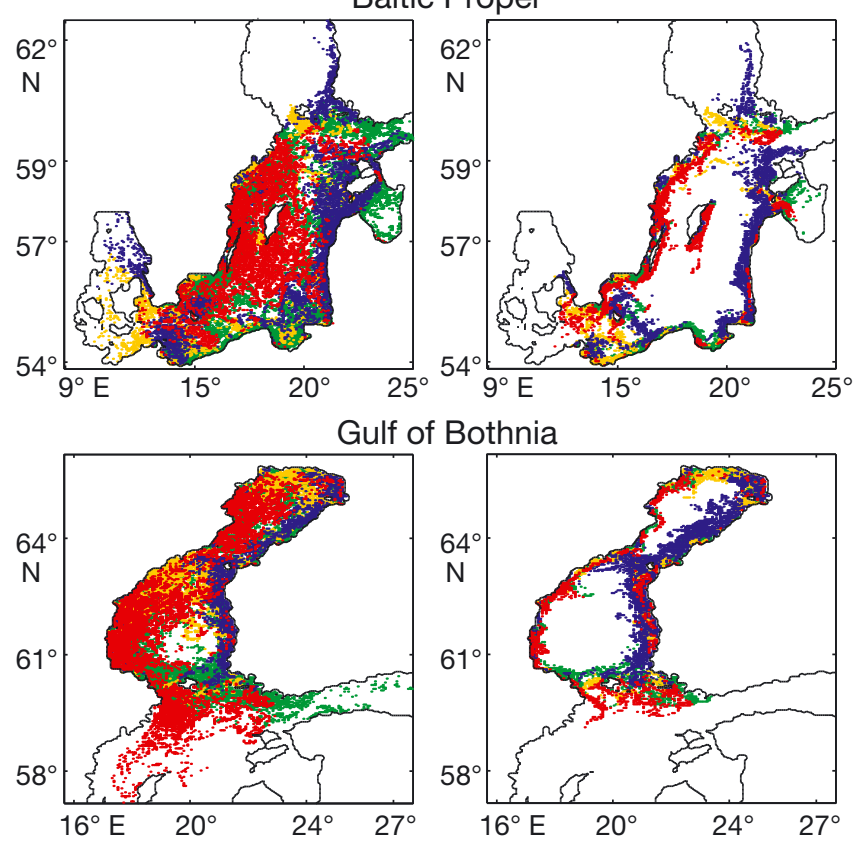

Fig. 7. End points of larval trajectories released in the 3 regions for surface and $30 \mathrm{~m}$ larvae, PLD $=40 \mathrm{~d}$. The colour of a grid cell represents the dominant direction travelled of the larval trajectories ending up there (see key). For clarity, the end points of the trajectories are binned into the grid cells of the model domain, and the dominant direction is shown. The number of end points per grid cell cannot be read in the figure

planktonic larvae. For almost a decade, many reports have emphasised the importance of including dispersal and connectivity in the selection of MPAs (e.g. Hastings \& Botsford 2003, Palumbi 2004, Jones et al. 2007, Almany et al. 2009), but in only a few cases (e.g. Gleason et al. 2010) has it been explicitly incorporated in the selection of MPA networks. This neglect is likely a consequence of both the difficulties involved in estimating marine dispersal and connectivity (e.g. Jones et al. 2009) but also the lack of a framework of how to include connectivity in MPA selection. There are still relatively few studies of how to use

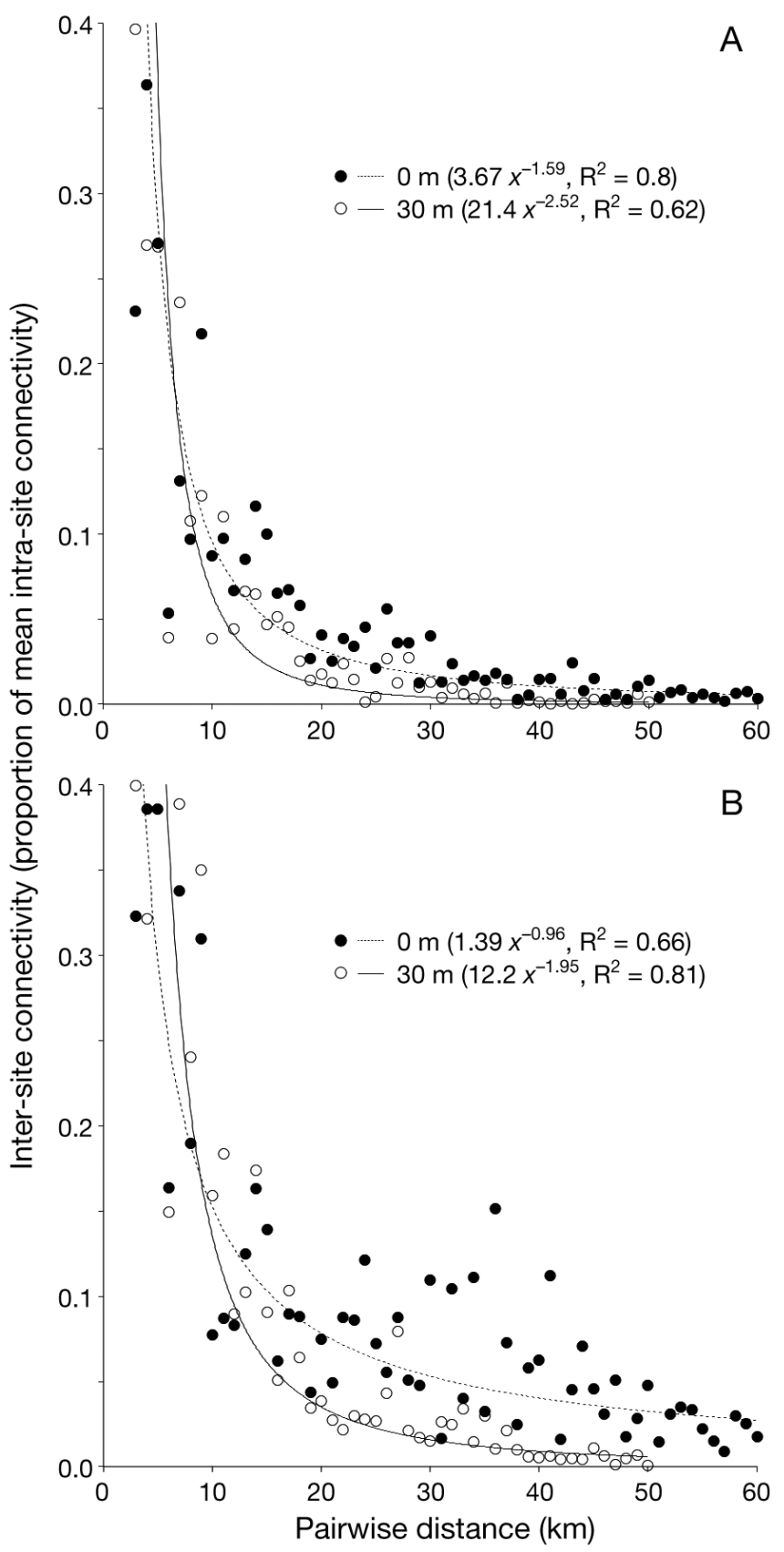

Fig. 8. Pairwise inter-site connectivities plotted against pairwise distance for 300 randomly selected sites $\left(3.7 \times 3.7 \mathrm{~km}^{2}\right)$. Connectivities are expressed as proportion of mean intra-site connectivity for the drift depths 0 and $30 \mathrm{~m}$ for PLD of (A) $10 \mathrm{~d}$ and (B) $40 \mathrm{~d}$. Also shown are fits to power regressions

connectivity information to guide practical MPA selection (Stockhausen et al. 2000, Lockwood 2002, Moffitt et al. 2011, Nilsson Jacobi \& Jonsson 2011).

A major objective of the present study is to improve estimates of dispersal by including information on where in the water column planktonic larvae are 
being dispersed and to explore how the dispersal depth and other larval traits, such as PLD and spawning season, affect connectivity and MPA functionality. In a field survey, we found that taxonomic groups differed significantly in their depth distribution, ranging from surface waters to $>100 \mathrm{~m}$ depth, well below the thermocline. These results are consistent with other field studies that have found taxonomic differences in the depth distribution of larvae, e.g. fish larvae (Munk \& Nielsen 2005), decapod crustaceans (Queiroga \& Blanton 2005, Yoshinaga et al. 2010) and bivalves (Ma et al. 2006). Based on empirically found dispersal depths, we then simulated larval dispersal trajectories along realistic coastlines in the Baltic Sea. The results show that dispersal depth was as important as PLD in determining net dispersal distance and that they together explained almost $80 \%$ of the total variation in dispersal distance. Surface-drifting larvae were on average transported more than twice the distance of larvae at $30 \mathrm{~m}$ depth. This strong effect of depth was consistent across regions, seasons and years, although we had selected 2 contrasting years from the North Atlantic Oscillation. In addition, dispersal direction changed with larval swimming depth, and the net transport was in some regions (the Danish Straits) in opposite directions at the surface and at $30 \mathrm{~m}$ depth. In the Baltic regions, coastal retention increased strongly with dispersal depth. Dispersal depth and PLD are influenced by biological factors on both ecological and evolutionary time scales. Depth may be controlled by behaviour, and PLD depends on temperature and food availability (e.g. O'Connor et al. 2007). Relatively rapid evolutionary change of PLD is supported by large differences between phylogenetically close taxa (e.g. McHugh \& Rouse 1998). This suggests that dispersal distance may be under strong biological control through changes in drift depth and PLD. It further shows that knowledge about species-specific vertical distribution and development time is critical when assessing the functionality of MPA networks for specific communities. We did not model more complex larval vertical behaviours, e.g. diel or tidal migration and ontogenetic shifts, which have been described for several decapod crustacean and fish species, predominantly in macro-tidal areas (Forward \& Tankersley 2001, Queiroga \& Blanton 2005). However, with the exception of bryozoan larvae, which were found deeper at higher light intensities, we did not detect any diurnal shifts with light regime, suggesting that diel vertical migration was rare among the assessed larval taxa. We also did not detect any ontogenetic changes in depth distribution, although low abundances and lack of taxonomic resolution only allowed for a test of cirriped larvae. Moreover, because of the micro-tidal conditions in the study area, selective tidal migration is unlikely and would only have negligible effects on dispersal (Queiroga et al. 2002). Thus, the empirical data suggest that fixed dispersal depths can be used to accurately model most larval taxa in this region.

Other similar studies have also found a clear effect of PLD on dispersal distance (e.g. Lefebvre et al. 2003, Siegel et al. 2003, Paris et al. 2007). However, effects of larval vertical swimming behaviour have been more varied (Metaxas \& Saunders 2009). Most biophysical models have focused on larval depth distributions or ontogenetic depth shifts characteristic of some target species (e.g. Paris et al. 2007, Xue et al. 2008, Bolle et al. 2009), and few studies have included generic variations in dispersal depth. Edwards et al. (2007) explored generic larval dispersal off the southeast coast of North America but only found a slight difference among 3 dispersal depths. Also, Savina et al. (2010) found little effects of 3 different vertical behaviours in lemon sole larvae in the North Sea. In contrast, biophysical models of scallop larvae around Georges Bank showed strongly reduced dispersal for larvae drifting at deeper depths (e.g. Tremblay et al. 1994). North et al. (2008) found that simulated vertical migration behaviour in oyster larvae had greater influence on dispersal than did interannual differences in circulation patterns, similar to the present results. In a biophysical model of dispersal in the Caribbean Sea, Cowen et al. (2000) concluded that larvae were retained closer to spawning sites when drifting deeper down in the water column. This reduced dispersal to offshore waters at greater depths is consistent with our findings in the Baltic Sea (Fig. 7).

The frequency distribution of modelled dispersal distance for the different larval types showed modes at 2 to $5 \mathrm{~km}$ with relatively low frequencies ( 2 to $8 \%$ ) and with fat tails towards longer distances. For trajectories in surface waters, $10 \%$ dispersed 30 to $160 \mathrm{~km}$, depending on PLD (Table 5). These distributions are similar to well-studied distributions of wind-dispersed seeds (e.g. Nathan et al. 2002) and are characterised by non-exponential declines in dispersal probability typical of multi-scale dispersal mechanisms (Shaw 1995). An important aspect is that such dispersal kernels may lead to both strong local recruitment and significant connectivity with more distant areas.

For the persistence of species in a MPA, the reproduction must either take place through local recruitment within a single MPA or through network persistence, in which larvae are imported from other MPAs 
(Hastings \& Botsford 2006). The median size of Natura 2000 MPAs in the shallow parts of the Baltic Sea is $8 \mathrm{~km}$, and $90 \%$ are $<22 \mathrm{~km}$ in diameter. In the present study, none of the modelled larval types would reach a local recruitment of $50 \%$ within these MPAs, and of all the larval taxa collected in the field study, only Bryozoa would have a local recruitment $>10 \%$ within these MPAs, based on their depth distribution and PLD (see Table S1 in the supplement). There was significant local variation in both estimated dispersal distances and MPA size. Generally, the correlation between MPA size and the expected median dispersal distance was low (Figs. $3 \& 6$ ), and the overall percentage of sufficiently large MPAs also remains low when local variation is accounted for. About $10 \%$ of the Natura 2000 MPAs are $>20 \mathrm{~km}$, but these are still too small to offer local recruitment over $50 \%$ to any of the larval types except for species with a PLD of $\leq 10 \mathrm{~d}$ and a dispersal depth of $\geq 10 \mathrm{~m}$. Since we did not include any mortality in the biophysical model, the proportion of local recruitment is expected to be even lower for larvae with longer PLD. The small size of MPAs in the Baltic Sea is not unique. Johnson et al. (2008) calculated that the 298 MPAs within the Natura 2000 system along the northeast Atlantic have a median size of only $3 \mathrm{~km}$. The conclusion is that the present size of individual MPAs within Natura 2000 is considerably below what is required for local persistence of most sessile invertebrates and sedentary fish.

When the dispersal distance is much greater than the practical size of MPAs, the solution generally proposed is to select networks of appropriately spaced MPAs to allow connectivity of protected species with long larval PLDs (e.g. Roberts et al. 2003, Moffitt et al. 2011). In the Baltic Sea, the median nearest neighbour distance for the shallow MPAs is $15 \mathrm{~km}$, which is very similar to the median of $21 \mathrm{~km}$ calculated for the northeast Atlantic MPAs (Johnson et al. 2008). This scale is more compatible with our modelled dispersal distances, and the potential for connectivity between nearest neighbours is expected to be high (Fig. 5). This is supported by a more detailed analysis of the pairwise connectivity between 300 sites (with the same size as median MPAs) where connectivities of at least $5 \%$ of local recruitment were found for inter-site distances of $15 \mathrm{~km}$ and even up to $50 \mathrm{~km}$ for the longest PLD (40 d) in surface waters (Fig. 8). These distances correspond well to the median of MPA nearest neighbour distance in the Baltic Sea. The power regressions of connectivity against distance suggest that connectivity declines faster with shorter PLD and with greater depths, which correspond to a shorter mean dispersal distance. Note that there is consider- able scatter of connectivities with distance, especially for drift in surface waters (Fig. 8), and this is even clearer if data is not binned (data not shown). For many pairs of sites showing similar distances, the connectivity may differ many-fold. This demonstrates that there is no single adequate spacing distance, but rather, this distance will differ throughout the study area, likely caused by local circulation patterns. Successful network persistence may, however, require connectivity between more sites than only nearest neighbours. For the shallow Natura 2000 MPAs, there are on average 5 MPAs within a radius of $63 \mathrm{~km}$ in the Baltic Sea. This indicates that the inter-site connectivity found in Fig. 8 is probably too low for efficient dispersal to multiple sites, and the opportunity for network persistence may be low. It is also important to point out that this assessment of dispersal distances and MPA size assumes isotropic dispersal. As is evident from the modelled trajectories, dispersal may be highly directional (Fig. 7). It is also evident from the bubble graph in Fig. 3 that there are meso-scale geographic differences in dispersal distance as well as bathymetric limitations for deep-water dispersal. The spatial variability in circulation makes general predictions of optimal MPA size and spacing difficult, increasing the risk of non-functional MPAs. This is also the conclusion of Nilsson Jacobi \& Jonsson (2011), who proposed a framework for selecting optimal networks of MPAs based on detailed connectivity information. They found that simulated networks of MPAs in the Baltic Sea differed in their efficiency by up to an order of magnitude depending on the geographic location of individual MPAs. Nevertheless, based on the frequency distribution of dispersal distance (Fig. 5) and pairwise connectivities (Fig. 8), the recruitment within MPAs ought to be higher with few larger MPAs than with several smaller. To also allow $50 \%$ local recruitment of surface-drifting larvae with PLDs $>20 \mathrm{~d}$, e.g. typical of many fish, an MPA must be at least $55 \mathrm{~km}$ in diameter. Only $\sim 1 \%$ of the Natura 2000 MPAs meet this criterion.

A potential problem with large-scale dispersal models, including the present one, is that they do not accurately resolve complex small-scale circulation along the coast (e.g. wave-dominated flow) that may retain larvae (Werner et al. 2007), resulting in an overestimation of dispersal distance. However, the mean dispersal distances found in the present paper are similar to empirical estimates and shorter than estimates from genetic models (Shanks 2009). The median dispersal distances estimated in our simulations ( 11 to $46 \mathrm{~km}$ for PLDs of 20 and $40 \mathrm{~d}$ ) are similar to the 11 to $82 \mathrm{~km}$ (mean $28 \mathrm{~km}$ ) for a PLD of $30 \mathrm{~d}$ 
found by Edwards et al. (2007) modelling dispersal off the coast of south-east USA. Significantly longer dispersal distances, $\sim 150 \mathrm{~km}$, were found for modelled larval dispersal in offshore waters in the tropical Pacific (Treml et al. 2008). Our empirical data also support that long-distance dispersal is common in the study system. Many of the collected larval taxa in the field survey spawn exclusively in shallow water habitats, including the blue mussel, barnacles, the sand and common goby, rock gunnel and straight-nose pipe fish (Muus \& Nielsen 1999). Still, they were found at several of the offshore sampling sites, 50 to $100 \mathrm{~km}$ away from the closest shallow water habitat. These species all have larvae in surface water (Fig. 2, Table S1 in the supplement ), and the offshore dispersal is consistent with our model results for surface swimming larvae (Fig. 7).

In summary, our study suggests that empirically found dispersal depths of invertebrate and fish larvae together with PLD are expected to strongly affect dispersal distance. Information about these larval traits for targeted organisms is therefore critical for the design of functional MPA networks. More empirical field studies are needed to overcome the present lack of information of most marine organisms' larval swimming behaviour. An alarming conclusion is that existing MPAs in Europe seem generally too small to allow local recruitment above $50 \%$ for most sessile invertebrates and sedentary fish. If local recruitment is too low to allow persistence of populations within single MPAs, sufficient connectivity between MPAs is required to provide import of recruits. Although MPA spacing is on a scale similar to larval dispersal distance, connectivity within the network is expected to be low and critically depends on the spatial location of MPAs. The challenge is to find MPA network topologies that can be functional for a number of target species with diverse life-history traits and different dispersal capacities. In future work, this network selection should include spatially explicit biophysical models that consider connectivities for complex circulation patterns and informed larval traits and are coupled to models of population dynamics (e.g. Moffitt et al. 2011, Nilsson Jacobi \& Jonsson 2011). However, a dominating factor that directly affects the persistence of MPA networks is the total area protected, which is mainly a social-economic issue. The ultimate test for the MPA approach is if loss of biodiversity and critical ecological services can be reversed. If this limitation of MPAs, e.g. due to poor local recruitment, cannot be addressed because of political constraints, this calls for other approaches (Mora \& Sale 2011).
Acknowledgements. The plankton survey was carried out by the EU BONUS+ project BAZOOCA (Baltic zooplankton cascades) in collaboration with the Swedish Meteorological and Hydrological Institute, which generously provided the present study with plankton samples. The analyses of fish larvae were carried out by in collaboration with the Swedish Board of Fisheries at Lysekil. We greatly appreciate the excellent work with the multinet sampling by M. Haraldson and C. Jaspers, the expert help by A. C. Rudolphi and F. Pleijel in the identification of fish and polychaete larvae, respectively, and C. Tiselius and Emelie Hallberg for professional work in the analyses of invertebrate larvae. Funding was provided through the Swedish Research Council, the Swedish Research Council Formas, the Centre for Marine Evolutionary Biology and the Bert Bolin Centre for Climate Research.

\section{LITERATURE CITED}

Aiken CM, Navarrete SA, Castillo M, Castilla JC (2007) Along-shore larval dispersal kernels in a numerical ocean model of the central Chilean coast. Mar Ecol Prog Ser 339:13-24

Almany GR, Connolly SR, Heath DD, Hogan JD and others (2009) Connectivity, biodiversity conservation and the design of marine reserve networks for coral reefs. Coral Reefs 28:339-351

Blanke B, Raynaud S (1997) Kinematics of the Pacific Equatorial Undercurrent: a Eulerian and Lagrangian approach from GCM results. J Phys Oceanogr 27: 1038-1053

> Bolle LJ, Dickey-Collas M, van Beek JKL, Erftemeijer PLA, Witte JIJ, van der Veer HW, Rijnsdorp AD (2009) Variability in transport of fish eggs and larvae. III. Effects of hydrodynamics and larval behaviour on recruitment in plaice. Mar Ecol Prog Ser 390:195-211

> Botsford LW, White JW, Coffroth MA, Paris CB and others (2009) Connectivity and resilience of coral reef metapopulations in marine protected areas: matching empirical efforts to predictive needs. Coral Reefs 28:327-337

> Caley MJ, Carr MH, Hixon MA, Hughes TP, Jones GP, Menge BA (1996) Recruitment and the local dynamics of open marine populations. Annu Rev Ecol Syst 27: 477-500

Carson HS, Cook GS, López-Duarte PC, Levin LA (2011) Evaluating the importance of demographic connectivity in a marine metapopulation. Ecology 92:1972-1984

Cowen RK, Sponaugle S (2009) Larval dispersal and marine connectivity. Annu Rev Mar Sci 1:443-466

Cowen RK, Kamazima MML, Sponaugle S, Paris CB, Olson DB (2000) Connectivity of marine populations: open or closed? Science 287:857-859

Cowen RK, Paris CB, Srinivasan A (2006) Scaling of connectivity in marine populations. Science 311:522-527

De Vries P, Döös K (2001) Calculating Lagrangian trajectories using time-dependent velocity fields. J Atmos Sci 18: 1092-1101

Diamond JM (1975) The island dilemma: lessons of modern biogeographic studies for the design of natural reserves. Biol Conserv 7:129-146

Döös K (1995) Inter-ocean exchange of water masses. J Geophys Res 100(C7):13499-13514

Döscher R, Willén U, Jones C, Rutgersson A, Meier HEM, Hansson U, Graham LP (2002) The development of the 
regional coupled ocean-atmosphere model RCAO. Boreal Environ Res 7:183-192

Edwards KP, Hare JA, Werner FE, Seim H (2007) Using 2dimensional dispersal kernels to identify the dominant influences on larval dispersal on continental shelves. Mar Ecol Prog Ser 352:77-87

Elken J, Matthäus W (2008) Baltic Sea oceanography. In: von Storch H, Omstedt A (eds) Assessment of climate change for the Baltic Sea basin. BALTEX Publications, Springer, Heidelberg, p 379-385

Fiksen Ø, Jørgensen C, Kristiansen T, Vikebø F, Huse G (2007) Linking behavioural ecology and oceanography: larval behaviour determines growth, mortality and dispersal. Mar Ecol Prog Ser 347:195-205

Forward RB (1988) Diel vertical migration: zooplankton photobiology and behaviour. Oceanogr Mar Biol Annu Rev 26:361-393

Forward RB, Tankersley RA (2001) Selective tidal-stream transport of marine animals In: Gibson RB, Barnes M, Atkinson RJA (eds) Oceanography and marine biology, Vol 39. Taylor \& Francis, London, p 305-353

> Gaines SD, Gaylord B, Largier JL (2003) Avoiding current oversights in marine reserve design. Ecol Appl 13: S32-S46

Gleason M, McCreary S, Miller-Henson M, Ugoretz J and others (2010) Science and stakeholder-driven marine protected area network planning: a successful case study from north central California. Ocean Coast Manage 53: $52-68$

> Halpern BS, Walbridge S, Selkoe KA, Kappel CV and others (2008) A global map of human impact on marine ecosystems. Science 319:948-952

Hanski I (1999) Metapopulation ecology. Oxford University Press, New York, NY

> Hastings A, Botsford LW (2003) Comparing designs of marine reserves for fisheries and for biodiversity. Ecol Appl 13:S65-S70

> Hastings A, Botsford LW (2006) Persistence of spatial populations depends on returning home. Proc Natl Acad Sci USA 103:6067-6072

HELCOM (2009). Protected Areas: Natura 2000 sites. http:// maps.helcom.fi/website/mapservice/index.html

Hibler WD (1979) A dynamic thermodynamic sea ice model. J Phys Oceanogr 9:815-846

> Hurrell JW, Deser C (2009) North Atlantic climate variability: the role of the North Atlantic Oscillation. J Mar Syst 78:28-41

> Incze L, Xue H, Wolff N, Xu D and others (2010) Connectivity of lobster (Homarus americanus) populations in the coastal Gulf of Maine: part II. Coupled biophysical dynamics. Fish Oceanogr 19:1-20

> Johnson MP, Crowe TP, Mcallen R, Allcock AL (2008) Characterizing the marine Natura 2000 network for the Atlantic region. Aquatic Conserv 18:86-97

> Jones GP, Srinivasan M, Almany GR (2007) Population connectivity and conservation of marine biodiversity. Oceanography (Wash DC) 20:100-111

> Jones GP, Almany GR, Russ GR, Sale PF, Steneck RS, van Oppen MJH, Willis BL (2009) Larval retention and connectivity among populations of corals and reef fishes: history, advances and challenges. Coral Reefs 28: 307-325

Kaplan DM, Botsford LW, Jorgensen S (2006) Dispersal per recruit: an efficient method for assessing sustainability in marine reserve networks. Ecol Appl 16:2248-2263
Kinlan BP, Gaines SD (2003) Propagule dispersal in marine and terrestrial environments: a community perspective. Ecology 84:2007-2020

Kritzer JP, Sale PF (2004) Metapopulation ecology in the sea: from Levins' model to marine ecology and fisheries science. Fish Fish 5:131-140

Lefebvre A, Ellien C, Davoult D, Thiébaut E, Salomon JC (2003) Pelagic dispersal of the brittle-star Ophiothrix fragilis larvae in a megatidal area (English Channel, France) examined using an advection/diffusion model. Estuar Coast Shelf Sci 57:421-433

Leppäranta M, Myrberg K (2009) Physical oceanography of the Baltic Sea. Springer-Praxis, Berlin

- Lester SE, Halpern BS, Grorud-Colvert K, Lubchenco J and others (2009) Biological effects within no-take marine reserves: a global synthesis. Mar Ecol Prog Ser 384: $33-46$

Lipcius RN, Ralph GM 2011. Evidence of source-sink dynamics in marine and estuarine species. In: Liu J, Hull V, Morzillo AT, Wiens JA (eds) Sources, sinks, and sustainability. Cambridge University Press, Cambridge, p 361-381

> Lipcius RN, Eggleston DB, Schreiber SJ, Seitz RD and others (2008) Importance of metapopulation connectivity to restocking and restoration of marine species. Rev Fish Sci 16:101-110

> Lockwood DR (2002) The effects of dispersal patterns on marine reserves: Does the tail wag the dog? Theor Popul Biol 61:297-309

Lotze HK, Lenihan HS, Bourque BJ, Bradbury RH and others (2006) Depletion, degradation, and recovery potential of estuaries and coastal seas. Science 312:1806-1809

Ma H, Grassle JP, Chant RJ (2006) Vertical distribution of bivalve larvae along a cross-shelf transect during summer upwelling and downwelling. Mar Biol 149:1123-1138

Mace PM (1994) Relationships between common biological reference points used as thresholds and targets of fisheries management strategies. Can J Fish Aquat Sci 51: $110-122$

Magaard L, Rheinheimer G (1974) Meereskunde der Ostsee. Springer-Verlag, Heidelberg

McHugh D, Rouse GW (1998) Life history evolution of marine invertebrates: new views from phylogenetic systematics. Trends Ecol Evol 13:182-186

Meier HEM (1999) First results of multi-year simulations using a 3D Baltic Sea model. SMHI Oceanography report, Sveriges Meteorologiska och Hydrologiska Institut, Norrköping

Meier HEM (2001) On the parameterization of mixing in three-dimensional Baltic Sea models. J Geophys Res 106(C12):30997-31016

Meier HEM, Döscher R, Faxén T (2003) A multi processor coupled ice-ocean model for the Baltic Sea: Application to salt inflow. J Geophys Res 108:3273

- Metaxas A, Saunders M (2009) Quantifying the 'bio-' components in biophysical models of larval transport in marine benthic invertebrates: advances and pitfalls. Biol Bull 216:257-272

Mitarai S, Siegel DA, Winters KB (2008) A numerical study of stochastic larval settlement in the California Current system. J Mar Syst 69:295-309

Moffitt EA, White JW, Botsford LW (2011) The utility and limitations of size and spacing guidelines for designing marine protected area (MPA) networks. Biol Conserv 144:306-318 
Mora C, Sale PF (2011) Ongoing global biodiversity loss and the need to move beyond protected areas: a review of the technical and practical shortcomings of protected areas on land and sea. Mar Ecol Prog Ser 434:251-266

Morgan SG (2001) The larval ecology of marine communities. In: Bertness MD, Gaines SD, Hay ME (eds) Marine community ecology. Sinauer Associates, Sunderland, MA, p 159-181

Munk P, Nielsen JG (2005) Eggs and larvae of North Sea fishes. Bifolia, Fredriksberg

Muus BJ, Nielsen JG (1999) Sea fish, Scandinavian Fishing Year Book. Hedehusene

- Nathan R, Katul GG, Horn HS, Thomas SM and others (2002) Mechanisms of long-distance dispersal of seeds by wind. Nature 418:409-413

Nilsson Jacobi M, Jonsson PR (2011) Optimal networks of nature reserves can be found through eigenvalue perturbation theory of the connectivity matrix. Ecol Appl 21: 1861-1870

> North EW, Schlag Z, Hood RR, Li M, Zhong L, Gross T, Kennedy VS (2008) Vertical swimming behavior influences the dispersal of simulated oyster larvae in a coupled particle-tracking and hydrodynamic model of Chesapeake Bay. Mar Ecol Prog Ser 359:99-115

O'Connor MI, Bruno JF, Gaines SD, Halpern BS, Lester SE, Kinlan BP, Weiss JM (2007) Temperature control of larval dispersal and the implications for marine ecology, evolution, and conservation. Proc Natl Acad Sci USA 104: 1266-1271

Pacanowski RC, Griffies SM (2000) MOM 3.0 manual. www. ocgy.ubc.ca/ yzq/books/MOM3/guide_parent.html

> Palumbi SR (2004) Marine reserves and ocean neighborhoods: the spatial scale of marine populations and their management. Annu Rev Environ Resour 29:31-68

Paris CB, Chérubin LM, Cowen RK (2007) Surfing, spinning, or diving from reef to reef: effects on population connectivity. Mar Ecol Prog Ser 347:285-300

> Possingham HP, Roughgarden J (1990) Spatial population dynamics of a marine organism with a complex life cycle. Ecology 71:973-985

Queiroga H, Blanton J (2005) Interactions between behaviour and physical forcing in the control of horizontal transport of decapod larvae. In: Southward A, Tyler P, Young C, Fuiman L (eds) Advances in marine biology, Vol 47. Elsevier Science, San Diego, CA, p 107-214

> Queiroga H, Moksnes PO, Meireles S (2002) Vertical migration behaviour in the larvae of the shore crab Carcinus maenas from a microtidal system (Gullmarsfjord, Sweden). Mar Ecol Prog Ser 237:195-207

Roberts CM (1997) Connectivity and management of Caribbean coral reefs. Science 278:1454-1457

Roberts CM, Branch G, Bustamante RH, Castilla JC and others (2003) Application of ecological criteria in selecting marine reserves and developing reserve networks. Ecol Appl 13:S215-S228

> Robinson CLK, Morrison J, Foreman MGG (2005) Oceanographic connectivity among marine protected areas on the north coast of British Columbia, Canada. Can J Fish Aquat Sci 62:1350-1362

Sale PF, Kritzer JP (2003) Determining the extent and spatial scale of population connectivity: decapods and coral reef fishes compared. Fish Res 65:153-172

Savina M, Lacroix G, Ruddick K (2010) Modelling the transport of common sole larvae in the southern North Sea: Influence of hydrodynamics and larval vertical movements. J Mar Syst 81:86-98

Seifert T, Kayser B (1995) A high resolution spherical grid topography of the Baltic Sea. Meereswiss Ber 9:73-88

Shanks AL (1995) Mechanisms of cross-shelf dispersal of larval invertebrates and fish. In: McEdward L (ed) Biology of marine invertebrate larvae. CRC Press, Boca Raton, FL, p 323-367

Shanks AL (2009) Pelagic larval duration and dispersal distance revisited. Biol Bull 216:373-385

> Shanks AL, Grantham BA, Carr MH (2003) Propagule dispersal distance and the size and spacing of marine reserves. Ecol Appl 13:S159-S169

> Shaw MW (1995) Simulation of population expansion and spatial pattern when individual dispersal distributions do not decline exponentially with distance. Proc R Soc Lond B 259:243-248

> Siegel DA, Kinlan BP, Gaylord B, Gaines SD (2003) Lagrangian descriptions of marine larval dispersion. Mar Ecol Prog Ser 260:83-96

Sinnott RW (1984) Virtues of the Haversine. Sky Telescope $68: 159$

Stockhausen WT, Lipcius RN, Hickey BM (2000) Joint effects of larval dispersal, population regulation, marine reserve design, and exploitation on production and recruitment in the Caribbean spiny lobster. Bull Mar Sci 66:957-990

> Tremblay MJ, Loder J, Werner F, Naimie C, Page F, Sinclair M (1994) Drift of sea scallop larvae Placopecten magellanicus on Georges Bank: a model study of the roles of mean advection, larval behavior and larval origin. DeepSea Res 41:7-49

> Treml EA, Halpin PN, Urban DL, Pratson L (2008) Modeling population connectivity by ocean currents, a graphtheoretic approach for marine conservation. Landscape Ecol 23:19-36

Underwood AJ (1996) Experiments in ecology: their logical design and interpretation using analysis of variance. Cambridge University Press, Cambridge

Werner FE, Cowen RK, Paris CB (2007) Coupled biological and physical models: present capabilities and necessary developments for future studies of population connectivity. Oceanography (Wash DC) 20:54-69

> White JW, Botsford LW, Hastings A, Largier JL (2010) Population persistence in marine reserve networks: incorporating spatial heterogeneities in larval dispersal. Mar Ecol Prog Ser 398:49-67

> Xue H, Incze L, Xu D, Wolff N, Pettigrew N (2008) Connectivity of lobster populations in the coastal Gulf of Maine. Part I: Circulation and larval transport potential. Ecol Modell 210:193-211

> Yoshinaga MY, Sumida PYG, Silveira ICA, Ciotti ÁM, Gaeta SA, Pacheco LFCM, Koettker AG (2010) Vertical distribution of benthic invertebrate larvae during an upwelling event along a transect off the tropical Brazilian continental margin. J Mar Syst 79:124-133

Submitted: October 7, 2011; Accepted: July 24, 2012

Proofs received from author(s): October 19, 2012
Editorial responsibility: Romuald Lipcius,

Gloucester Point, Virginia, USA 